\title{
The American Board of Family Medicine: What's Next?
}

\author{
Warren Newton, MD, MPH
}

In March 2004, the Future of Family Medicine issued a famous prophecy: "Unless there are changes in the broader health care system and within the specialty, the position of family medicine in the United States will be untenable in a 10- to 20-year time frame $^{1}$." Now, 15 years later, where are we?

The picture is mixed. The Affordable Care Act has increased access to care for many, chronic care and electronic health records (EHRs) are now integral to our practice, and there has been a proliferation of new practice models. But we are far short of where we need to be. Rapid health system consolidation, large-scale employment of physicians, and the rapid spread of high-deductible insurance plans may undermine robust primary care. Despite much public rhetoric on the importance of primary care in health system reform, the increase in US medical students choosing Family Medicine has been modest. At the practice level, EHRs can take attention away from the patient, burnout is epidemic, and improvements in quality and equity have often been local, modest, and temporary.

In this context, the American Board of Family Medicine (ABFM) believes that we must act with urgency, thoughtfulness, and passion. In the fall of 2018, we began a strategic planning process. Over the last 17 years, the ABFM, guided by its Board of Directors and Dr. James Puffer, has implemented many innovations to improve the certification portfolio, transformed the ABFM into a digital enterprise, and helped drive innovation in family medicine residency training. ${ }^{2,3}$ Dr. Puffer also launched a robust research enterprise ${ }^{4}$ that has documented positive correlations between certification and knowledge, quality of care, and lower incidence of adverse medical license action, in addition the dramatic changes in scope of care provided by family physicians. Where do we go now?

Conflict of interest: The author is the President of the American Board of Family Medicine.
The first question of our strategic planning process was, "What will the personal physician look like in 15 years?", especially as care is transformed by health system consolidation, technology changes such as artificial intelligence, genomics and telehealth, and new business combinations across commercial sectors such as the combination of Aetna and CVS Pharmacy. We believe strongly that there will continue to be an important role for the personal physician and that any attempt to address the triple aim-better health, better patient experience at lower cost-must include a robust primary care system. We also believe that family physicians' scope of care will need to extend significantly-to include, for example, more care of patients with multi-morbidities, integration of behavioral health, improving the effectiveness of transitions of care and the healing of inequities in communities. We also believe that individual family physicians will likely play a number of different roles over their careers.

The core role of ABFM will thus be to support our Diplomates to become and stay master clinicians, building on the skills they develop in residencies and adapting to what their communities need. At the same time, we will maintain and improve the components of our certification program that assure our patients and the public that those who are Board Certified are up-to-date, continually improve the care they provide, and are worthy of their trust. Our first step in this direction is the launch of Family Medicine Certification Longitudinal Assessment ${ }^{5}$ an option to the 1-day-every-10year examination, which provides summative assessment flexibly over time, while supporting learning and retention of information. While specifics of our plan to evolve certification are still being developed, we envision rapid evolution of our Board Certification programs over the next 5 years.

Engaging Diplomates in new ways will be essential to improving family medicine certification. Our community is large and diverse, and family physi- 
cians follow many different career paths, but we are committed to traveling the journey with them. Diplomate input will help guide the development of our programs, within a framework of standards that everyone can trust. We will work closely with our partners at the American Academy of Family Physicians (AAFP), state chapters, our academic communities and other partners to support our Diplomates' commitment to keep up to date and to improve the care they provide.

We are also committed to serving the specialty of Family Medicine. On a daily basis, we now work closely with the AAFP and its chapters, and we collaborate on residency innovation with the Association of Family Medicine Residency Directors, the development of clinician-scientists and research with the Association of Departments of Family Medicine, the North American Primary Care Research Group and many investigators, plus support the Society of Teachers of Family Medicine's efforts to develop preceptors. We look forward to identifying other ways to work with our partners. Throughout, we will regularly ask the questions: Are our programs effective? Are they valuable for Diplomates, patients, and the public?

Over the longer term, we will devote some of our attention more broadly-engaging our patients, our profession, and society. Building on our experience involving patients in their care and the contributions of the patient and public members on our Board, we will advocate for broad involvement of patients in all aspects of care, from shared decision making and patient-reported outcomes to collaboration in quality improvement, research, and the day-to-day management of health care. ${ }^{6}$ Outside of family medicine, as we work with other specialties and professions, we will champion ongoing and significant reforms in our health care system. We believe that our contract with society requires us to address the fundamental issues of health care in our time-the need for dramatic improvement in quality, cost-effectiveness, patient experience, and the wellbeing of our clinicians and their teams. We believe that if we do not address these issues, society will do it for us. This has already happened with the opioid crisis, as state legislatures step in where organized medicine's response has been too late and too little.

Our work will need many partners. A key early step is the founding of the Center for Professionalism and Value in Health Care in July 2019. Led by Executive Director Bob Phillips, MD, MSPH, the Center will seek to define what value means across the health care spectrum, reaching beyond medicine to engage the broader health care community as well as patients and families to consider what they believe professionalism and value mean, how to measure it, how to improve it, and how to engage and develop leaders. The Center will also take over existing ABFM activities such as the PRIME registry (an outpatient qualified clinical data registry), the Population Health Assessment Engine tool to help family physicians address social determinants in their practices, and our efforts to develop, test, and implement quality measures that better capture the value of primary care. We welcome collaboration with all others interested in professionalism and value in health care, including other specialty boards, other professions, and other organizations interested in working together on this common ground.

Given both the amplitude and uncertainty of change we face in health care, it is important to articulate explicitly the principles that will guide our actions as we move forward:

1. We will support clinical mastery among family physicians and excellence in their clinical teams.

2. We will engage Diplomates, appreciating the variety of practices and communities they serve.

3. We will model being a learning organization; we will change what we do in response to what we learn.

4. We will use evidence to drive our policies and programs.

5. We will commit to continuous improvement.

Will we-the specialty and the ABFM-succeed? Will family medicine become more robust and foundational to our health care system? As we chart this course, the pendulum is swinging away from personal physicians who offer care for the whole person over time, and there are grounds for pessimism. Burnout among family physicians is high, ${ }^{7,8}$ approximately 1 in 5 of our graduates do not have continuity practices 3 years after they graduate, ${ }^{9}$ and there has been rapid narrowing of the scope of practice. ${ }^{7}$

But there are grounds for hope as well. There is great promise in some of the new models of care, emerging data analytics that can identify the patients and problems we need to focus on, and new teletechnology that may support broadening the family 
physician's central role in delivering continuous comprehensive care. At a personal level, we are inspired when we see what family physicians and their practices are doing to improve care. We are inspired by family physicians who take a lead in addressing and reversing health inequity in their communities. We are inspired by the principled advocacy at the national and state levels to promote Family Medicine and Primary Care-and we are excited for the future of our specialty by the talented individuals emerging into leadership roles.

Fifty years ago, when the ABFM was founded, the Board chose the phoenix as a symbol of the rebirth of family medicine from general practice. We affirm again that symbol, as we work to support the renaissance of the personal physician, her team and the systems that make primary care robust.

We believe that the times we are living in are consequential. By working together, we can make a difference.

We look forward to hearing from you.

Warren Newton, MD, MPH.

To see this article online, please go to: http://jabfm.org/content/ 32/2/282.full.

\section{References}

1. Martin JC, Avant RF, Bowman MA, et al. The Future of Family Medicine: A collaborative project of the family medicine community. Ann Fam Med 2004; 2(Suppl 1):S3-S32.

2. Carney PA, Eiff MP, Waller E, Jones SM, Green LA. Redesigning residency training: Summary findings from the preparing the personal physician for practice (P4) project. Fam Med 2018;50:503-517.

3. Newton WP, Baxley EG. Preparing the personal physician for practice: What we've learned and where we need to go. Fam Med 2018;50:499-500.

4. ABFM Research. Available from: https://www.theabfm. org/research/index.aspx. Accessed January 10, 2019.

5. Longitudinal assessment exam alternative pilot description. Available from: https://www.theabfm.org/ moc/fmcla.aspx. Accessed January 10, 2019.

6. Patient and Family Engagement. A partnership for culture change. A report of the NCIOM Task Force on Patient and Family Engagement 2015. Available from: http://nciom.org/wp-content/uploads/2017/07/ Patient-FamilyEngage_Report-FINAL.pdf. Accessed January 10, 2019.

7. Weidner AKH, Phillips RL Jr., Fang B, Peterson LE. Burnout and scope of practice in new family physicians. Ann Fam Med 2018;16:200-205.

8. Puffer JC, Knight HC, O’Neill TR, et al. Prevalence of burnout in board certified family physicians. J Am Board Fam Med 2017;30:125-126.

9. Rassolian M, Peterson LE, Fang B, et al. Workplace factors associated with burnout of family physicians. JAMA Intern Med 2017;177:1036-1038. 